\title{
Diferentes níveis proteicos no crescimento de juvenis de Macrobrachium pantanalense
}

\author{
De Freitas, E. 1,2@; Passos, F.² e Hayd, L. ${ }^{2}$
}

Universidade de Aveiro. UA. Portugal.

2Universidade Estadual do Mato Grosso do Sul. UEMS. Brasil.

\section{PALAVRAS CHAVE ADICIONAIS}

Camarão de água doce.

Comprimento.

Desenvolvimento.

Nutriç̃õo.

Proteína.

\section{RESUMO}

O camarão de água doce do Pantanal, Macrobrachium pantanalense, é uma espécie promissora para ser utilizada na aquicultura ornamental. O objetivo deste estudo foi avaliar o crescimento de juvenis de $M$. pantanalense submetidos a dietas contendo diferentes níveis proteicos. O delineamento experimental foi ao acaso, contendo 4 tratamentos $(30,35,40$ e $45 \%$ PB), com 5 repetições, utilizando 5 animais em cada unidade experimental. Juvenis com peso médio inicial de 0,13 $\pm 0,02 \mathrm{~g}$ e comprimento total médio de $25,44 \pm 2,15 \mathrm{~mm}$ foram cultivados em 20 tanques de 10 litros em sistema de recirculação fechado dinâmico durante 90 dias. Após o término do cultivo, os animais foram mensurados e os dados submetidos à análise de variância (ANOVA). Não foram encontradas diferenças significativas $(p>0,05)$ entre os tratamentos para comprimento total $(\mathrm{mm})$, peso final $(\mathrm{g} e \%)$, taxa de crescimento específico (\%/dia) e conversão alimentar aparente. Sendo assim, indicamos o nível de $30 \%$ de PB para o cultivo de juvenis de M. Pantanalense, considerando o mesmo crescimento em relação aos demais níveis proteicos avaliados e por apresentar o menor custo para a confecção da ração.

\section{Different protein levels on Macrobrachium pantanalense juvenile growth}

\section{SUMMARY}

\section{ADDITIONAL KEYWORDS}

Freshwater prawn.

Length.

Development.

Nutrition.

Protein.

\section{INFORMACIÓN}

Cronología del artíiculo.

Recibido/Received: 04.06.2015

Aceptado/Accepted: 09.12.2015

On-line: 16.03 .2016

Correspondencia a los autores/Contact e-mail:

eduardozootecnia@gmail.com

\section{INTRODUÇÃO}

Dentro dos setores da aquicultura, a criação de camarões de água doce tem apresentado elevado crescimento em todo o mundo (Valenti, 2002; New 2005; New et al. 2010) tendo como principal representante a espécie Macrobrachium rosenbergii (220.254 toneladas / ano de produção) (FAO, 2014). O Brasil apresenta uma rica e diversa fauna de camarões de água doce, porém, apenas três espécies possuem potencial produtivo para o mercado alimentar, tais como: Macrobrachium acanthurus, M. carcinus e M. amazonicum (Kutty e Va- lenti, 2010; Moraes-Valenti e Valenti, 2010). Camarões de água doce também podem ser destinados a outras modalidades produtivas como a aquicultura ornamental e aquariofilia (Jayalal e Ramachandran, 2012; Karim et al., 2015), de forma sustentável buscando expandir o uso de espécies nativas e reduzir a exploração de recursos naturais (Kimpara et al., 2010; Valenti, 2008, 2012).

O camarão-do-pantanal, Macrobrachium pantanalense, anteriormente conhecido como $M$. amazonicum, foi recentemente descrito como uma nova espécie (Dos 
Santos et al., 2013), apresentando diferenças morfológicas, anatômicas, fisiológicas e comportamentais em relação ao camarão-da-amazônia, $M$. amazonicum (Dos Santos et al., 2013; Weiss et al., 2015). O camarão M. pantanalense é encontrado em abundância no Pantanal Sul Matogrossense, mede de 20 a $70 \mathrm{~mm}$ de comprimento total, apresenta coloração transparente (Hayd e Anger, 2013), possui comportamento ativo na coluna d'água e aptidão para cultivo integrado a outros organismos aquáticos (Karim et al., 2015). Apresenta larvicultura, berçário e crescimento final simplificados, com suporte de vida adaptado a pequenas propriedades (Karim et al., 2015). M. pantanalense vem sendo amplamente estudado no Pantanal Sul Matogrossense em relação aos aspectos reprodutivos (Hayd e Anger, 2013; Vercesi e Hayd, 2015), salinidade (Lopes, 2013), densidade de estocagem (Caballero, 2013) e desenvolvimento larval.

Na carcinicultura de água doce, a alimentação representa de 50 a $70 \%$ dos custos produtivos (Akiyama et al., 1991; Lim et al., 1997; Shiau, 1998; Martínez-Cordova et al., 2003). A proteína é o componente mais oneroso no processo de fabricação de rações, (Farmanfarmaian e Lauterio, 1980; Martínez-Cordova et al., 2003) sendo um dos principais constituintes na dieta dos crustáceos (Cortes-Jacinto et al., 2003; Kabir Chowdhury et al., 2008; Espinosa-Chaurand et al., 2012). São fundamentais para a manutenção do funcionamento vital, reprodução e crescimento (Guillaume, 1997). Apesar disso, seu uso está diretamente relacionado com os custos de produção (Lemos et al., 2009), sendo um fator crucial na viabilidade econômica do cultivo (Hari e Kurup, 2003).

A maior dificuldade na nutrição de camarões dulcícolas é a confecção de dietas que atendam com precisão suas exigências nutricionais. Alguns autores indicam que o nível excelente de proteína bruta $(\mathrm{PB})$ para juvenis de $M$. rosenbergii está entre 30 a $35 \%$ (Zimmermann, 1998; D'Abramo e New, 2010). Pezzato et al. (2003) identificaram que juvenis de $M$. amazonicum apresentam ótimos índices zootécnicos quando alimentados com 35\% PB. Já Luna et al. (2007) observaram melhores rendimentos de peso em juvenis de $M$. rosenbergii alimentados com 25 \% PB. Urbano et al. (2010) obtiveram maior ganho de peso e comprimento total com $28 \%$ PB na dieta em juvenis de Macrobrachium jelskii.

M. pantanalense é uma espécie descrita recentemente, e possui exigências nutricionais específicas que precisam ser estudadas, uma vez que ainda não há nenhum tipo de informação sobre as exigências deste crustáceo. Desta forma, a identificação do nível proteico é fundamental para o aperfeiçoamento do seu pacote tecnológico de cultivo. Assim, este trabalho teve como objetivo identificar o melhor nível de proteína bruta para ser utilizado na dieta de juvenis de $M$. pantanalense.

\section{MATERIAL E MÉTODOS}

O trabalho foi conduzido no Laboratório de Carcinologia, Carcinicultura e Ornamentais da Universidade Estadual do Mato Grosso do Sul (CARCIPANTA - UEMS) localizada no município de Aquidauana - MS (Altitude $184 \mathrm{~m}, 20^{\circ} 28^{\prime} \mathrm{S}, 55^{\circ} 48^{\prime} \mathrm{W}$ ), no período de
Tabela I. Dietas experimentais (ingredientes e composição centesimal, com base na matéria seca) com diferentes níveis de proteína bruta para juvenis de Macrobrachium pantanalense (Experimental diets (ingredients, centesimal composition, based on the dry matter) with differents crude protein levels to Macrobrachium pantanalense juvenile).

\begin{tabular}{|c|c|c|c|c|}
\hline \multicolumn{5}{|c|}{ Dietas experimentais (\% PB) } \\
\hline Ingredientes (\%) & $30 \%$ & $35 \%$ & $40 \%$ & $45 \%$ \\
\hline Milho, fubá & 0,391 & 0,253 & 0,153 & 0,052 \\
\hline Soja, farelo (45\%) & 0,150 & 0,296 & 0,220 & 0,163 \\
\hline Vísceras, farinha de aves & 0,160 & 0,175 & 0,310 & 0,375 \\
\hline Soja, óleo & 0,015 & 0,019 & 0,013 & 0,004 \\
\hline Peixe, farinha $(61 \%)$ & 0,270 & 0,244 & 0,290 & 0,393 \\
\hline Premix $^{1}$ & 0,012 & 0,012 & 0,012 & 0,012 \\
\hline $\mathrm{BHT}^{2}$ & 0,002 & 0,002 & 0,002 & 0,002 \\
\hline Total & 1,000 & 1,000 & 1,000 & 1,000 \\
\hline \multicolumn{5}{|c|}{ Composição centesimal } \\
\hline latéria seca *,\% & 89,73 & 89,87 & 90,71 & 91,26 \\
\hline Proteína bruta *,\% & 29,69 & 35,06 & 41,00 & 46,02 \\
\hline Energia digestível ${ }^{* *}(\mathrm{kcal} / \mathrm{kg})$ & 3201,74 & 3230,37 & 3248,49 & 3244,82 \\
\hline Extrato etéreo ${ }^{*} \%$ & 6,91 & 7,11 & 8,26 & 8,41 \\
\hline Fibra bruta * $\%$ & 1,51 & 2,03 & 1,44 & 0,96 \\
\hline Material mineral ${ }^{*}, \%$ & 8,53 & 9,11 & 11,60 & 14,25 \\
\hline
\end{tabular}

${ }^{1}$ Premix vitamínico e mineral-composição (por kg de produto/ Migfish 1\%): Ác. Fólico: 299,88 mg; Ác. Ascórbico: 15.000,12 mg; Ác. Pantotênico: 3.000,10 mg; Biotina: 0,06 mg; Niacina (B3): $9.000,32 \mathrm{mg}$; Colina (B4): 103.500,00 mg; Vit. A: 1.000.000,00 Ul; Vit. B1: 1.500,38 mg; Vit. B2: $1.500,0 \mathrm{mg}$; Vit. B6: $1.500,38 \mathrm{mg}$; Vit. D3: $240.000,00 \mathrm{UI}$, Vit. E: $10.000,00 \mathrm{mg}$; Vit. K3: 400,00 mg; Inositol: 9.999,92 mg; Ferro: 6.416,80 mg; Manganês: 8.000,40 mg; Cobre: 1.000,00 mg; Zinco: $13.999,50 \mathrm{mg}$; lodo: 45,36mg; Cobalto: 60,06 mg; Selênio: 60,30 mg; Magnésio: 5,10 mg; Cloro: 2,30\%, Enxofre: 0,01\%. ${ }^{2}$ Butil hidróxitolueno (BHT); *Com base em análises de laboratório (LNA/ UEMS); ${ }^{* *}$ Com base nos valores propostos para o camarão Litopenaeus vannamei, segundo o NRC (2011) e por Rostagno et al. (2011).

março a junho de 2014. Foram utilizados 100 juvenis do camarão-do-pantanal, M. pantanalense, coletados na lagoa Baiazinha localizada no município de Miranda - MS (2016" S e 56 $23^{\circ}$ "W). Os animais apresentaram peso médio inicial de 0,13 $\pm 0,02 \mathrm{~g}$; comprimento total (CT) de 25,44 $\pm 2,15$ mm e comprimento de cefalotórax (CC) de 5,45 $\pm 0,57 \mathrm{~mm}$. Após a biometria, os animais foram estocados em 20 tanques de polietileno de cor preta (volume útil de 10 litros) controladas com entrada/saída de água individuais por meio de sistema de recirculação de água fechado dinâmico, durante 90 dias, com temperatura e aeração controladas para cada unidade.

Utilizou-se um delineamento inteiramente casualizado (DIC), com 4 níveis de proteína bruta como tratamentos (30, 35, 40 e 45 \% PB) e 5 repetições, contendo 5 animais em cada unidade experimental. As rações experimentais possuíam formulação isoenergética (3200 $\mathrm{kcal} \mathrm{kg}^{-1}$ ), cujas composições percentuais, calculadas e análises bromatológicas encontram-se na tabela I. Os ingredientes foram homogeneizados e, posteriormente, hidratados para peletização. Os peletes foram secos em estufa de ventilação forçada, durante 24 horas a $55^{\circ} \mathrm{C}$, e processados para a obtenção de grânulos com diâmetro de 0,1 mm, adaptado da metodologia empregada por 
Tabela II. Valores médios ( \pm desvio-padrão) dos parâmetros de qualidade de água no cultivo de juvenis de Macrobrachium pantanalense alimentados com diferentes níveis de proteína bruta (Mean values ( \pm standard deviation) of water quality parameters in reared of Macrobrachium pantanalense juvenile fed differents crude protein levels).

\begin{tabular}{|c|c|c|c|c|}
\hline \multirow[b]{2}{*}{ Parâmetros } & \multicolumn{4}{|c|}{ Dietas experimentais (\% PB) } \\
\hline & $30 \%$ & $35 \%$ & $40 \%$ & $45 \%$ \\
\hline Temperatura $\left({ }^{\circ} \mathrm{C}\right)$ & $28,98 \pm 0,63$ & $29,29 \pm 0,56$ & $29,02 \pm 0,59$ & $29,22 \pm 0,46$ \\
\hline Condutividade elétrica $\left(\mathrm{mS} / \mathrm{cm}^{-1}\right)$ & $0,50 \pm 0,59$ & $0,64 \pm 0,68$ & $0,68 \pm 0,73$ & $0,63 \pm 0,78$ \\
\hline Salinidade & $0,24 \pm 0,28$ & $0,31 \pm 0,21$ & $0,33 \pm 0,30$ & $0,31 \pm 0,20$ \\
\hline Oxigênio dissolvido (mg/L-1) & $7,68 \pm 0,19$ & $8,02 \pm 0,21$ & $7,86 \pm 0,26$ & $7,92 \pm 0,31$ \\
\hline $\mathrm{pH}$ & $8,40 \pm 0,44$ & $8,45 \pm 0,40$ & $8,44 \pm 0,46$ & $8,43 \pm 0,40$ \\
\hline $\mathrm{NH}_{3}\left(\mathrm{mg} / \mathrm{L}^{-1}\right)$ & $0,21 \pm 0,04$ & $0,20 \pm 0,05$ & $0,24 \pm 0,02$ & $0,23 \pm 0,02$ \\
\hline $\mathrm{NO}_{2}\left(\mathrm{mg} / \mathrm{L}^{-1}\right)$ & $0,03 \pm 0,02$ & $0,03 \pm 0,01$ & $0,04 \pm 0,03$ & $0,02 \pm 0,01$ \\
\hline
\end{tabular}

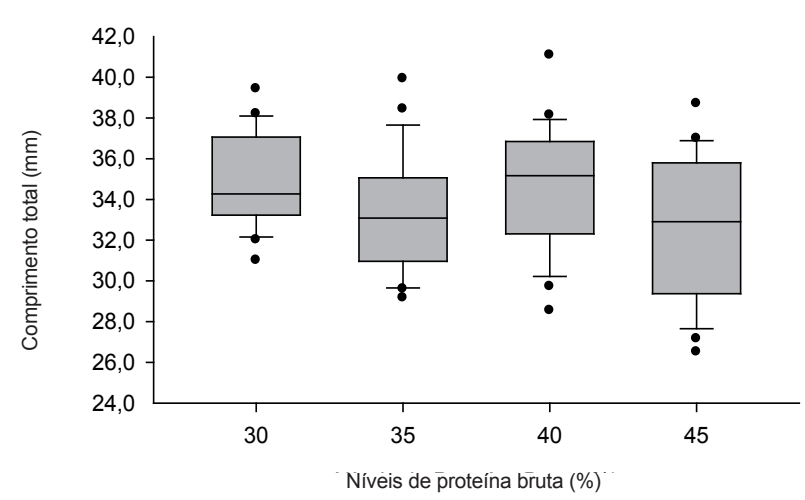

Figura 1. Valores da mediana e extremos do comprimento total (mm) em juvenis de Macrobrachium pantanalense alimentados com diferentes níveis de proteína bruta (Median and extreme values of the total lenght $(\mathrm{mm})$ in Macrobrachium pantanalense juvenile fed on different crude protein levels).

Pezzato et al. (2003). As dietas foram formuladas com base nas composições da matéria seca dos ingredientes apresentados por Rostagno et al. (2011) e as exigências nutricionais para o camarão Litopenaeus vannamei de acordo com o NRC (2011), exceto para os níveis de PB. As análises bromatológicas das rações foram realizadas no Laboratório de Nutrição Animal (LNA) da UEMS, conforme metodologia descrita por Detmann et al. (2012).

A alimentação foi realizada duas vezes ao dia, às 09:00 h e 16:00 h e a limpeza das unidades experimentais foi realizada às 08:00 h. Diariamente, foram aferidos parâmetros como temperatura $\left({ }^{\circ} \mathrm{C}\right), \mathrm{pH}$ e oxigênio dissolvido na água $\left(\mathrm{mg} \mathrm{L}^{-1}\right)$, e duas vezes na semana os demais parâmetros condutividade elétrica $\left(\mathrm{mS} \mathrm{cm}^{-1}\right)$, salinidade, amônia $\left(\mathrm{NH}_{3}\right)$ e nitrito $\left(\mathrm{NO}_{2}\right)$. As biometrias foram realizadas no início do experimento (uniformidade dos animais) e ao término dos 90 dias. Utilizou-se uma balança analítica adventurer (OHAUS) e um paquímetro digital (Digimess) com precisão de $0,0001 \mathrm{~g}$ e $0,01 \mathrm{~mm}$, respectivamente.

Foram avaliados os seguintes parâmetros de crescimento: peso final (PF): massa corporal obtida ao final do experimento, em gramas; ganho de peso (GP): acréscimo de massa corporal obtida entre a primeira e última biometria, em gramas; ganho de peso (\%): GP $(\%)=($ massa corporal final-massa corporal inicial $) /$ massa corporal inicial ${ }^{*} 100$; comprimento total $(\mathrm{CT})$ : medida da ponta do rostro até o final do telson, em $\mathrm{mm}$; percentual de animais com CT acima de $34 \mathrm{~mm}$ $(\mathrm{CT}, \%)$ - contagem de todos os animais que obtiveram CT superior a $34 \mathrm{~mm}$, expresso em percentual; taxa de crescimento específico (\%/dia): TCE $=($ ln massa corporal final-ln massa corporal inicial)/(dias)*100; e conversão alimentar aparente: $\mathrm{CAA}=$ (peso da ração fornecida no período)/(peso final-peso inicial), calculada segundo Pezzato et al. (2003).

Os dados foram submetidos à análise de normalidade pelo teste de Kolmogorov-Smirnov. Com as condições atendidas, as médias dos parâmetros de qualidade de água (temperatura, condutividade elétrica, oxigênio dissolvido, salinidade, $\mathrm{pH}$, nitrito e amônia e das variáveis de produção (CT, PF, GP, TCE e CAA) foram submetidas a análise de variância (one-way ANOVA) $(p<0,05)$ afim de aferir a influência dos níveis de PB na dieta sobre os resultados obtidos. Realizou-se também uma análise de regressão de mínimos quadrados entre as variáveis de desempenho de crescimento (PF, GP, TCE e CAA) e os níveis de PB, para obter a equação de regressão e o coeficiente de correlação $\left(R^{2}\right)$. As análises estatísticas foram realizadas por meio do programa estatístico SigmaPlot 11.0.

\section{RESULTADOS E DISCUSSÃO}

Os parâmetros de qualidade de água não apresentaram diferenças significativas entre os tratamentos ( $p>0,05)$, ou seja, as diferentes concentrações proteicas das dietas não interferiram nos parâmetros limnológicos (tabela II). Foram encontrados na literatura resultados similares, que correspondem às exigências para sistemas de cultivo do gênero Macrobrachium (Zimmerman, 1998).

Não houve diferença significativa $(p>0,05)$ para o CT em função dos níveis de proteína bruta na dieta (figura 1). Todos os tratamentos resultaram em camarões com tamanho médio acima de $34 \mathrm{~mm}$, demonstrando que as dietas utilizadas foram satisfatórias para o crescimento, porém, nos níveis de 30 e $40 \%$ foi obtido percentual maior de indivíduos com esta medida (tabela III). Este tamanho médio também é utilizado em outas espécies de camarões ornamentais de pequeno porte, como demonstrado por Mary e Chockley (2003) em Stenopus hispidus, com machos entre CT de 40 a $50 \mathrm{~mm}$ e fêmeas entre 45 a $50 \mathrm{~mm}$ e Lin 
Tabela III. Valores médios ( \pm desvio-padrão) para os parâmetros de crescimento avaliados no cultivo de juvenis de Macrobrachium pantanalense alimentados com diferentes níveis de proteína bruta (Mean values ( \pm standard deviation) for growth parameters evaluted in reared of Macrobrachium pantanalense juvenile fed differents crude protein levels).

\begin{tabular}{lcccc}
\hline & \multicolumn{4}{c}{ Dietas experimentais (\% PB) } \\
\cline { 2 - 5 } Parâmetros & $30 \%$ & $35 \%$ & $40 \%$ & $45 \%$ \\
\hline Comprimento total (\%) & 60 & 32 & 56 & 36 \\
Peso final (g) & $0,28 \pm 0,04$ & $0,27 \pm 0,02$ & $0,29 \pm 0,02$ & $0,25 \pm 0,03$ \\
Ganho de peso (g) & $0,15 \pm 0,04$ & $0,14 \pm 0,02$ & $0,16 \pm 0,02$ & $0,12 \pm 0,03$ \\
Ganho de peso (\%) & $122,24 \pm 34,24$ & $109,58 \pm 18,83$ & $128,67 \pm 20,86$ & $96,84 \pm 27,81$ \\
TCE (\%/dia) & $0,88 \pm 0,12$ & $0,89 \pm 0,18$ & $0,90 \pm 0,14$ & $0,71 \pm 0,20$ \\
CAA & 3,33 & 3,58 & 3,04 & 4,27 \\
\hline
\end{tabular}

TCE $=$ Taxa de crescimento específico; CAA= Conversão alimentar aparente.

e Shi (2002) em juvenis de Stenopus scutellatus, com CT entre 34 a $39 \mathrm{~mm}$. Em estudos com outras espécies do gênero Macrobrachium, em que foram utilizados níveis proteicos similares aos deste ensaio, foi possível obter adultos de Macrobrachium tenellum com 32 a $41 \mathrm{~mm}$ (Espinosa-Chaurand et al., 2012; García-Ulloa Gómez et al., 2008) e de M. jelskii com 45 a $51 \mathrm{~mm}$ (Urbano et al., 2010). Isso demonstra que o uso de dieta com baixos níveis proteicos $(30 \% \mathrm{~PB})$ pode produzir indivíduos com comprimento comercial similar a níveis superiores de proteína, sem afetar o desempenho de crescimento dos animais.

Os valores médios do PF (g); GP (g e \%), TCE (\%) e CAA, também não diferiram significativamente $(p>0,05)$ entre os tratamentos (tabela III).

Observou-se que o GP foi positivo em todos os níveis de proteína das dietas experimentais, demonstrando que seria interessante avaliar o uso de níveis inferiores de proteína e aferir o desempenho a partir destes. Os valores de proteína bruta para ganho de peso observados neste ensaio são similares aos encontrados na literatura para juvenis de $M$. rosenbergii de forma que, os maiores pesos finais foram registrados por Hari e Kurup (2003) com a dieta contendo 30\% PB; Teshima et al. (2006) com 40\% PB; AL-Hafedh (2007) com 35 a $40 \%$ PB; Luna et al. (2007) com 25\% PB; Gupta et al. (2007) com 35\% PB; Hossain e Islam (2007) com $32,5 \%$ PB; Goda (2008) com 30\% PB e Amaraweera et al. (2014) com $30 \%$ PB. Outras concentrações proteicas da dieta que resultaram em maior peso final foram registrados em outras espécies do gênero Macrobrachium. M. tenellum com dieta contendo $40 \%$ PB (García-Ulloa Gomez et al., 2008; Espinosa-Chaurand et al., 2012). M. jelskii, com $28 \%$ PB (Urbano et al., 2010), Macrobrachium nipponense com 38\% PB (Yang et al., 2004) e Macrobrachium dayannum com $40 \%$ PB (Langer et al., 2011).

Em resultados percentuais, observou-se que os níveis de 30, 35 e 40\% PB apresentaram resultados superiores a $100 \%$. Estes valores demonstram que os animais obtiveram crescimento positivo, talvez por sua exigência proteica ter sido atendida desde o primeiro nível, enfatizando que a elevação do nível de proteína na dieta não produzirá indivíduos com maior peso. Além disso, o aproveitamento da proteína pelos camarões pode ser otimizado pelo uso do menor nível proteico associado com uma redução do período de cultivo na fase de berçário. García-Ulloa Gómez et al.
(2008) e Espinosa-Chaurand et al. (2012) obtiveram melhor percentual de ganho de peso com $40 \%$ PB na dieta de juvenis de M. tenellum, enquanto Langer et al. (2011) alcançaram maior percentual de ganho de peso, $60 \%$ para $M$. dayannum, ambos inferiores ao encontrado neste ensaio. Para M. amazonicum, Pezzato et al. (2003) observaram elevado ganho de peso em juvenis alimentados com dieta contendo $35 \%$ PB. Em M. rosenbergii vários autores demonstraram elevados valores de percentual de ganho de peso, variando entre 30 e $40 \%$ de PB na dieta (Ashmore et al., 1985; Hari e Kurup, 2003; Teshima et al., 2006; AL-Hafedh, 2007; Hossain e Islam, 2007; Luna et al., 2007; Goda, 2008; Kabir Chowdhury et al., 2008; Amaraweera et al., 2014). Jones et al. (1996) obtiveram ótimos resultados em percentual de ganho de peso com 30\% PB na dieta de Cherax destructor, similar ao visualizado neste experimento. $\mathrm{O}$ ganho de peso avaliado neste ensaio serviu para comparar apenas o desenvolvimento de alguns camarões dulcícolas ao camarão-do-Pantanal, porém, este não é o objetivo principal a ser alcançado na produção de camarões ornamentais, uma vez que, comprimento e largura são mais apreciados pelo mercado da aquariofilia que o peso da produção.

A TCE de M. pantanalense foi satisfatória em todos os tratamentos. Uma vez que a exigência proteica foi baixa, todos os tratamentos resultaram em ótimo tamanho comercial dos camarões. Considerando que M. pantanalense é uma espécie ornamental, os valores de TCE registrados são aceitáveis, no qual, o peso da produção possui menor valor comercial agregado ao produto final. Em outros crustáceos dulcícolas observou-se valores de TCE similares aos deste ensaio: $1,67 \%$ para $M$. tenellum (Espinosa-Chaurand et al., 2012); 1,02\% para M. jelskii (Urbano et al., 2010); 0,88\% para M. nipponense (Yang et al., 2004). Considerando também que $M$. pantanalense é uma espécie de pequeno porte, seu crescimento diário é diferente de espécies como $M$. rosenbergii onde os valores de TCE registrados na literatura encontram-se entre 1,21 a 3,72\% (Hari e Kurup, 2003; AL-Hafedh, 2007; Hossain e Islam, 2007; Gupta et al., 2007; Amaraweera et al., 2014). CortesJacinto et al. (2003) obtiveram maior TCE em juvenis de Cherax quadricarinatus com 31 \% $\mathrm{PB}$, similar ao obtido neste teste.

Em todos os tratamentos a CAA não apresentou bons resultados. Talvez um dos motivos seja uma baixa 
Tabela IV. Equações de regressão e coeficientes de correlação entre os parâmetros avaliados e os níveis de proteína bruta para juvenis de Macrobrachium pantanalense (Regression equations and correlation coefficients between evaluted parameters and crude protein levels to Macrobrachium pantanalense juvenile).

\begin{tabular}{llc}
\hline Parâmetros & Equação de regressão & Coeficiente de correlação $\left(R^{2}\right)$ \\
\hline Peso final $(\mathrm{g})$ & $\mathrm{Y}=-0,0004 \mathrm{X}+0,2933$ & 0,03 \\
Ganho de peso $(\mathrm{g})$ & $\mathrm{Y}=-0,0004 \mathrm{X}+0,1633$ & 0,03 \\
Taxa de crescimento específico - TCE (\%/dia) & $\mathrm{Y}=-0,0057 \mathrm{X}+1,0785$ & 0,20 \\
Conversão alimentar aparente - CAA & $\mathrm{Y}=0,0066 \mathrm{X}+1,4640$ & 0,10 \\
\hline
\end{tabular}

digestibilidade destes animais em relação aos ingredientes utilizados na confecção da ração, uma vez que o conhecimento da digestibilidade dos alimentos, para esta espécie, é inexistente. Os valores de CAA obtidos foram similares e distintos dos verificados na literatura. $M$. tenellum apresentou CAA de 1,34 e 2,39 com $40 \%$ PB na dieta (García-Ulloa Gómez et al., 2008; EspinosaChaurand et al., 2012). Pezzato et al. (2003) observaram valores de 2,20 com 30\% PB em $M$. amazonicum, com o menor nível proteico testado. Em $M$. rosenbergii vários valores de CAA foram registrados: 2,56 (Ashmore et al., 1985); 2,84 (Hari e Kurup, 2003); 3,20 (AL-Hafedh, 2007); 3,15 (Gupta et al., 2007); 1,73 (Hossain e Islam, 2007); 1,50 (Luna et al., 2007); 2,21 (Kabir Chowdhury et al., 2008); 1,60 e 2,47 a 2,84 (Amaraweera et al., 2014). Cortes-Jacinto et al. (2003) obtiveram CAA de 1,07 no desenvolvimento de juvenis de C. quadricarinatus. Talvez os valores de CAA obtidos neste ensaio possam estar relacionados com o metabolismo animal, de forma que a absorção da proteína pode ser afetada pelo baixo metabolismo na fase de cultivo, como Campaña-Torres et al. (2008) observaram que a conversão e a digestibilidade pode mudar em função da fase de cultivo.

As equações de regressão demonstraram que não houve efeito significativo em nenhum dos parâmetros avaliados $(p>0,05)$ (tabela IV). Os resultados também corroboram que a variação no nível proteico não afetou de forma positiva ou negativa o desempenho de crescimento, diferente de Hari e Kurup (2003), CortesJacinto et al. (2003) e Espinosa-Chaurand et al. (2012), que encontraram efeito de regressão entre PF, GP e TCE com os níveis de proteína testados em diferentes crustáceos dulcícolas.

O desenvolvimento de estudos nutricionais para camarões de água doce, em especial do gênero $M a-$ crobrachium, ainda são limitados, principalmente para determinação de exigências nutricionais, avaliação e digestibilidade de alimentos, tempo de passagem no trato digestório e outros. A escolha do nível de 30\% como controle partiu da exigência para juvenis de $M$. rosenbergii demonstrado por D’Abramo e New (2010). Observa-se ainda uma variação de níveis proteicos para o cultivo de juvenis de várias espécies de crustáceos. Isto pode estar relacionado aos seguintes fatores: sistemas de cultivo, tipo, qualidade e digestibilidade de alimentos utilizados na confecção de rações, parâmetros de qualidade de água, entre outros. A literatura apresenta o uso de 25 a 51 \% PB para crustáceos em geral. No caso de camarões de água doce, o intervalo está entre 30 a $40 \%$ PB (D’Abramo e New, 2010).

Animais que atendem o mercado da aquariofilia possuem suportes de vida específicos, já que o objeti- vo é produzir indivíduos diferenciados. Este mercado pode ser considerado seletivo já que o preço atribuído ao produto não é agregado ao peso da produção, mas sim no valor unitário. Karim et al. (2015) demonstraram que unidades de juvenis de $M$. pantanalense podem ser comercializados no valor de $\mathrm{R} \$ 3,00$ (cotado a $\mathrm{R} \$ 2,05$. Logo, \$1,45). Em função do volume de produção ser menor, a viabilidade econômica do cultivo é viável, já que $M$. pantanalense pode ser alimentado com dieta contendo $30 \%$ PB, apresentando ótimos índices de desenvolvimento e redução dos custos com alimentação.

\section{CONCLUSÃO}

Não houve diferença para nenhum dos níveis de proteína bruta no desenvolvimento dos juvenis, entretanto, ao considerar que $M$. pantanalense é uma espécie direcionada ao mercado da aquicultura ornamental, o uso de $30 \%$ PB na dieta é viável, já que o percentual de animais produzidos com tamanho comercial é aceitável, otimizando assim, o uso da proteína e reduzindo o custo financeiro na confecção de rações.

\section{AGRADECIMENTOS}

Ao Dr. Ricardo Calado da Universidade de Aveiro - Portugal e a Fundação de Apoio ao Desenvolvimento do Ensino, Ciência e Tecnologia do Estado do Mato Grosso do Sul - FUNDECT, pela bolsa de mestrado.

\section{BIBLIOGRAFIA}

Akiyama D.M.; Dominy, W.G. and Lawrence, A.L. 1991. Penaeid shrimp nutrition for the commercial feed industry (DM Akiyama, Ed.). 1 st ed. American Soybean Association. EUA.

Al-Hafedh, Y.S. 2007. Effects of dietary protein level on growth, feed conversion, and protein efficiency ratio of freshwater prawn, Macrobrachium rosenbergii, in outdoor concrete tanks. J Appl Aquac, 19: 51-60.

Amaraweera, K.; Wijeyaratne, M. and Jayamanne, S. 2014. Growth and survival of post-larvae of giant freshwater prawn (Macrobrachium rosenbergii) reared using feeds formulated with different sources of protein. Sri Lanka J Aquat Sci, 18: 17-26.

Ashmore, S.B.; Stanley, R.W.; Moore, L.B. and Malecha, S.R. 1985. Effect on growth amd apparent digestibility of diets varying in grain source and protein level in Macrobrachiurn rosenbergii. JWorld Maric Soc, 16: 205-216.

Boyd, C. and Zimmermann, S. 2010. Grow-out - Water quality and soil management. In: New, M.B.; Valenti, W.C.; Tidwell, J.H.; D'Abramo, L.R. and Kutty, M.N. (Eds.). Freshwater Prawns: Biology and Farming, 1st ed. Wiley. Blackwell. EUA. pp. 241-255. 
Campaña-Torres, A.; Martínez-Cordova, L.R.; Villarreal-Colmenares, H. and Civera-Cerecedo, R. 2008. Carbohydrate and lipid digestibility of animal and vegetal ingredients and diets for the pre-adult redclaw crayfish, Cherax quadricarinatus (von Martens). Aquac Res, 39: 1115-1121.

Caballero, L.O. 2013. Efeito de diferentes estratégias alimentares e densidades de estocagem para o camarão do pantanal, Macobrachium spp. Dissertação de Mestrado. Aquidauana. Universidade Estadual do Mato Grosso do Sul. Mato Grosso do Sul.

Cortes-Jacinto, E.; Villarreal-Colmenares, H.; Civera-Cerecedo, R. and Martínez-Cordova, R. 2003. Effect of dietary protein level on growth and survival of juvenile freshwater crayfish Cherax quadricarinatus (Decapoda: Parastacidae). Aquac Nutr, 9: 207-213.

D'Abramo, L.R. and New, M.B. 2010. Nutrition, Feeds and Feeding. In: New, M.B.; Valenti, W.C.; Tidwell, J.H.; D'Abramo, L.R. and Kutty, N. (Eds.). Freshwater prawns: Biology and farming, 1st ed. WileyBlackwell. EUA. 570 pp.

Detmann, E.; Souza M.A.; Valadares Filho, S.C.; Queiroz, A.C.;Berchielli, T.T.; Saliba, E.O.S. and Azevedo, J.A.G. 2012. Métodos para análise de alimentos. (Suprema, Ed.), $1^{a}$ ed. Visconde do Rio Branco. MG.

Dos Santos, A.; Hayd, L. and Anger, K. 2013. A new species of Macrobrachium Spence Bate, 1868 (Decapoda, Palaemonidae), M. pantanalense, from the Pantanal, Brazil. Zootaxa, 3700: 534-546.

Espinosa-Chaurand, L.; Flores-Zepeda, C.; Nolasco-Soria, H.; CarrilloFarnes, O. y Vega-Villasante, F. 2012. Efecto del nivel proteico de la dieta sobre el desarrollo de juveniles de Macrobrachium tenellum (Smith, 1871). Rev MVZ Córdoba, 17: 3140-3146.

FAO 2014. Production statistics - Cultured aquatic species information programme Macrobrachium rosenbergii (De Man, 1879). Cult Aquat Species Inf Program Macrobrachium rosenbergii (De Man, 1879).

Farmanfarmaian, A. and Lauterio, T. 1980. Amino acid composition of the tail muscle of Macrobrachium rosenbergii - comparison to amino acid patterns of supplemented commercial feed pellets. Proc World Maricul SOC, 11: 454-462.

García-Ulloa Gómez, M.; López-Aceves, L.A.; Ponce-Palafox, J.T.; Rodríguez-González, H. and Arredondo-Figueroa, J.L. 2008. Growth of fresh-water prawn Macrobrachium tenellum (Smith, 1871) juveniles fed isoproteic diets substituting fish meal by soya bean meal. Brazilian Arch Biol Technol, 51: 57-65.

Goda, A.M.A.S. 2008. Effect of dietary protein and lipid levels and protein-energy ratio on growth indices, feed utilization and body composition of freshwater prawn, Macrobrachium rosenbergii (De Man 1879) post larvae. Aquac Res, 39: 891-901.

Guillaume, J. 1997. Protein and amino acids. Crustac Nutr 6: 26-50.

Gupta, A.; Sehgal, H.S. and Sehgal, G.K. 2007. Growth and carcass composition of giant freshwater prawn, Macrobrachium rosenbergii (De Man), fed different isonitrogenous and isocaloric diets. Aquac Res, 38: 1355-1363.

Hari, B. and Kurop, M.B. 2003. Comparative evaluation of dietary protein levels and plant-animal protein ratios in Macrobrachium rosenbergii (De Man). Aquac Nutr, 9: 131-137.

Hayd, L. and Anger, K. 2013. Reproductive and morphometric traits of Macrobrachium amazonicum (Decapoda: Palaemonidae) from the Pantanal, Brazil, suggests initial speciation. Rev Biol Trop, 63: 39-57.

Hossain, A.M. and Islam, F.S. 2007. Meat and bone meal as partial substitute for fish meal in nursery diet for giant freshwater prawn, Macrobrachium rosenbergii (De Man). J World Aquac Soc, 38: 272-280.

Jayalal, L. and Ramachandran, A. 2012. Export trend of Indian ornamental fish industry. Agric Biol J North Am, 3: 439-451.

Jones, P.L.; De Silva, S.S. and Mitchell, B.D. 1996. Effects of replacement of animal protein by soybean meal on growth and carcass composition in juvenile Australian freshwater crayfish. Aquac Int, 4: 339-359.

Kabir-Chowdhury, M.A.; Goda, A.M.A.S.; El-haroun, R.E.; Wafa, M.A. and Salah El-Din, S.A. 2008. Effect od dietary protein and feeding time os growth performance and feed utilization of post larval freshwater prawn Macrobrachium rosenbergii (De man, 1879). J Fish Aquat Sci, 3: 1-11.
Karim, H.M.; Freitas, J.E.C.; Lima, T.P.C.; Nascimento, M.S. e Hayd, L. 2015. Viabilidade econômica da produção do camarão-do-pantanal (Macrobrachium pantanalense). Bol Inst Pesca, 41: 103-112.

Kimpara, J.M.; Zajdband, A.D. e Valenti, W.C. 2010. Medindo a sustentabilidade na aquicultura. Bol Ablimno, 38: 1-13.

Kubitza, F. 2003. Qualidade da água no cultivo de peixes e camarões, $1^{a}$ ed. Universidade Estadual Paulista (UNESP). Jundiaí.

Kutty, M.N. and Valenti, W.C. 2010. Culture of other freshwater prawn species. In: New, M.B.; Valenti, W.C.; Tidwell, J.H.; D'Abramo, L.R. and Kutty, M.N. (Eds.). Freshwater prawns: Biology and farming, 1st ed. Wiley-Blackwell. EUA. 570 pp.

Langer, S.; Bakhtiyar, Y. and Lakhnotra, R. 2011 . Replacement of fishmeal with locally available ingredients in diet composition of Macrobrachium dayanum. African J Agric Res, 6: 1080-1084.

Lemos, D.; Lawrence, A.L. and Siccardi, A.J. 2009. Prediction of apparent protein digestibility of ingredients and diets by in vitro $\mathrm{pH}$-stat degree of protein hydrolysis with species-specific enzymes for juvenile Pacific white shrimp Litopenaeus vannamei. Aquaculture, 295: 89-98.

Lim, C.; Beames, R.M.; Eales, J.G.; Prendergast, A.F.; McLeese, J.M.; Shearer, K.D. and Higgs, D.A. 1997. Nutritive values of low and high fibre canola meals for shrimp (Penaeus vannamei). Aquac Nutr, 3: 269-279.

Lin, J. and Shi, H. 2002. Effect of broodstock diet on reproductive performance of the golden banded coral shrimp Stenopus scutellatus. J World Aquac Soc, 33: 383-386.

Lopes, C.L. 2013. Desenvolvimento larval em diferentes salinidades e crescimento de juvenis de Macrobrachium sp. Dissertação de Mestrado. Universidade Estadual do Mato Grosso do Sul. Aquidauana. Mato Grosso do Sul.

Luna, M.; Graziani, C.; Villarroel, E.; Lemus, M.; Lodeiros, C. y Salazar, G. 2007. Evaluación de tres dietas con diferente contenido proteico en el cultivo de postlarvas del langostino de río Macrobrachium rosenbergii. Zootec Trop, 25: 111-121.

Martínez-Córdova, L.R.; Campana-Torres, A. and Porchas-Cornejo, M.A. 2003. Dietary protein level and natural food management in the culture of blue (Litopenaeus stylirostris) and white shrimp (Litopenaeus vannamei) in microcosms. Aquac Nutr, 9: 155-160.

Mary, C.M.S. and Chockley, B.R. 2003. Effects of body size on growth, survivorship, and reproduction in the banded coral shrimp, Stenopus Hispidus. J Crustac Biol, 23: 836-848.

Moraes-Valenti, P. and Valenti, W.C. 2010. Culture of the Amazon river prawn Macrobrachium amazonicum. In: New, M.B.; Valenti, W.C.; Tidwell, J.H.; D'Abramo, L.R. and Kutty, M.N. (Eds.). Freshwater prawns: biology and farming, 1st ed. Wiley-Blackwell. EUA. pp. 485-497.

NRC. 2011. Animal nutrition series national research council of the National Academies, fish and shrimps. The National Academies Press. Washigton. DC. USA.

New, M.B. 2005. Freshwater prawn farming: global status, recent research and a glance at the future. Aquac Res, 36: 210-230.

New, M.B.; Valenti, W.C.; Tidwell, J.H.; D'Abramo, L.R. and Kutty, M.N. (Eds.). 2010. Freshwater prawns: biology and farming, 1 st ed. Wiley-Blackwell. EUA.

Pezzato, L.E.; Barros, M.M.; Sampaio, F.G.; Falcon, R.; Sampaio, G. e Hisano, H. 2003. Relação energia:proteína dietária para pós-larvas de Macrobrachium amazonicum (Crustacea , Decapoda). Acta Sci, 25: 235-241.

Rostagno, H.S.; Albino, L.F.T.; Donzele, J.L.; Gomes, P.C.; Oliveira, R.F.; Lopes, D.C.; Ferreira, A.S.; Barreto, S.L.T. e Euclides, R.F. 2011 . Tabelas brasileiras para aves e suínos: composição de alimentos e exigências nutricionais., $3^{a}$ ed. Universidade Federal de Viçosa. Viçosa. MG.

Shiau, S. 1998. Nutrient requirements of penaeid shrimps. Aquaculture, 168: 14-17.

Teshima, S.; Koshio, S.; Ishikawa, M.; Alam, M.S. and Hernández Hernández, L.H. 2006. Protein requirements of the freshwater prawn Macrobrachium rosenbergii evaluated by the factorial method. JWorld Aquac Soc, 37: 145-153. 
Urbano, T.; Silva, A.A.; Medina, L.; Moreno, C.; Guevara, M. y Graziani, C. 2010. Crecimiento del camarón de agua dulce Macrobrachium jelskii (Miers, 1877), en lagunas de cultivo. Zootec Trop, 28: 163-172.

Valenti, W.C. 2002. Situação atual, perspectivas e novas tecnologias para produção de camarões de água doce. In: 12 Simpósio Brasileiro de Aqüicultura. Goiânia-GO. pp. 99-106.

Valenti, W.C. 2008. A aquicultura brasileira é sustentável. Aqüicultura and Pesca, 34: 36-44.

Valenti, W.C. 2012. Avanços e desafios tecnológicos para a sustentabilidade da carcinicultura transformação. In: $49^{\circ}$ Reunião Anual da Sociedade Brasileira de Zootecnia. A produção animal no mundo em transformação. Brasilia. DF.

Vercesi, K. e Hayd, L. 2015. Avaliação do número de ovos em diferentes estágios de desenvolvimento embrionário de Macrobrachium pantanalense. Bol Inst Pesca 41: 655-663.

Vercesi, K. 2014. Avaliação da perda de embriões e efeito da inanição na sobrevivência de larvas de Macrobrachium pantanalense em di- ferentes salinidades. Dissertação de Mestrado. Universidade Estadual do Mato Grosso do Sul. Aquidauana. Mato Grosso do Sul.

Weiss, R.; Anger, K.; Hayd, L. and Schubart, C.D. 2015. Interpreting genetic distances for species recognition: the case of Macrobrachium amazonicum and the recently described M. pantanalense (Decapoda, Palaemonidae) from Brazilian freshwaters. Crustaceana, 88:11111126.

Yang, Y.; Xie, S.; Lei, W.; Zhu, X. and Yang, Y. 2004. Effect of replacement of fish meal by meat and bone meal and poultry by-product meal in diets on the growth and immune response of Macrobrachium nipponense. Fish Shellfish Immunol, 17: 105-14.

Zimmermann, S. 1998. Manejo de alimentos e alimentação dos camarões. In: Valenti, W.C. (Ed.). Carcinicultura de água doce: tecnologia para produção de camarões. 1 st ed. Instituto brasileiro do meio ambiente e dos recursos naturais renováveis. Brasilia. DF. 386 pp. 
